\title{
Etnociências e Autossustentabilidade de Povos Tradicionais - Dossiê
}

\author{
Ethnosciences and Self-sustainability of Traditional Peoples - Dossier
}

Etnociencias y autosostenibilidad de los pueblos tradicionales - Dosier

ORGANIZADORES:

Natalino Perovano Filho' 1 iD

Universidade Estadual do Sudoeste da Bahia (Brasil)

Emilia Afonso Nhalevilo2

Universidade Púnguè (Moçambique)

Geilsa Costa Santos Baptista 3 iD

Universidade Estadual de Feira de Santana (Brasil)

Hilbert Blanco-Álvarez ${ }^{4}$ iD

Universidad de Nariño (Colômbia)

Dossiê | Dossier | Dosier

DOI do artigo: 10.22481/odeere.v6i2.10107

\section{Submetido em: 29/12/2021 | Aceito em: 29/12/2021}

Tem ocorrido um crescimento das produções realizadas a cerca das discussões das Relações étnicas, Etnicidades, Culturas, bem como sobre os processos de manutenção e continuidade dos Povos Tradicionais ao longo do tempo e na atualidade.

Na Região Sudoeste da Bahia, por exemplo, desde 2005, no ODEERE - Órgão de Educação de Relações Étnicas da Universidade Estadual do Sudoeste da Bahia (UESB), tem sido realizadas discussões e pesquisas sobre as temáticas, através de cursos de extensão, de Especialização e, a partir de 2014, a criação do Programa de Pós-Graduação em Relações étnicas e contemporaneidade, o qual já teve 8 turmas de discentes que tem realizado pesquisas com as temáticas indicadas acima.

Durante a realização da XV Semana de Educação da Pertença Afro-

\footnotetext{
1 Doutorado em 2016 (UESC), Docente permanente do Programa de Pós-Graduação em Relações Étnicas e Contemporaneidade. E-mail: npfilho@vesb.edu.br

2 Doutora e Mestre em Educação pela Universidade de Perth, Austrália e Licenciada em Engenharia de Educação pela Universidade Pedagógica (UP). Atualmente Reitora da Universidade Púngue Moçambique. E-mail: emiliafonso@gmail.com

3 Doutorado em Ensino, Filosofia e História das Ciências pela UFBA (2012), com estágio na Universidade do Minho, Portugal. Professora Titular no Departamento de Educação da Universidade Estadual de Feira de Santana. E-mail: geilsabaptista@gmail.com

4Profesor del Departamento de Matemáticas y Estadística, Universidad de Nariño, Pasto, Colombia. E-mail: director@etnomatematica.org
} 
Brasileira, realizada na UESB em 2019, ao participar da mesa redonda intitulada "COMUNIDADES, SUSTENTABILIDADE E POLÍtICAS PÚBLICAS", tendo com participantes dela a Profa. Dra. Ana Angélica Leal Barbosa, a Profa. Dra. Soraya Mendes Rodrigues Adrorno, o Prof. Especialista Eritan e o Prof. Dr. Natalino Perovano Filho. Na ocasião da realização desta mesa, os participantes foram instados a criar um grupo de pesquisa sobre a temática discutida. Em 2019 foi criado o grupo de pesquisa como nome ETNOCIÊNCIAS E AUTOSSUSTENTABILIDADE DE POVOS TRADICIONAIS", tendo o Prof. Dr. Natalino como seu líder.

O nome deste grupo está sendo utilizado como título deste Dossiê que teve por objetivo reunir produções de pesquisas, originais e inéditas, que abordam as discussões relacionadas aos conhecimentos, procedimentos e conceitos científicos e de sustentabilidade, desenvolvidos e realizados nos diferentes processos culturais dos Povos Tradicionais.

Conforme indicado por Silva e Fraxe (2013), Etnociências mobiliza, principalmente, os saberes das populações tradicionais que não são ou estão codificados pelos cientistas bem como os conhecimentos que determinados povos possuem. Tais saberes e conhecimentos são pesquisados, discutidos e apresentados a partir de suas diferenças nos aspectos sociais e/ou culturais.

Tendo em vista o que foi apresentado até o momento, apresentaremos a sequência de temas abordados nos artigos que foram submetidos e aprovados para este Dossiê.

No artigo que abre nosso Dosiê, "Los conocimientos tradicionales en el ejercicio de la soberanía y seguridad alimentaria de las comunidades rurales, indígenas y campesinas, una alternativa para la sustentabilidad comunitária", os autores apresentam reflexões sobre a importância de resgatar os conhecimentos tradicionais e os aspectos da sustentabilidade das comunidades. Neste texto foi realizada uma revisão bibliográfica e puderam verificar os processos que são necessários para a diversidade de culturas e, com isso, auxiliar as comunidades a eliminar os efeitos da pobreza e consolidar uma proposta alternativa para $O$ exercício da soberania (HERRERA; BARBOSA, 2021).

O segundo artigo, intitulado "Etnoconhecimento Terena na literatura científica: um estudo bibliográfico para o Estado da Arte", tem como foco principal o Povo Terena, predominantemente do Mato Grosso do Sul, sobre o qual tem sido 
realizadas pesquisas, além de existirem membros dos Terenas atuando em pesquisas. Em virtude do acima descrito, os autores buscaram realizar o Estado da Arte do etnoconhecimento Terena, através de revisão sistemática da (VILARIM; MARTINS; RODRIGUES, 2021).

O povo mais populoso do Sul do Brasil e que está entre os mais numerosos povos indígenas do país é o Povo Kaingang. No artigo "Conhecimento tradicional Kaingang: o uso de ervas medicinais" os autors buscaram realizar uma pesquisa de campo em uma Terra Indígena Kaingang no Paraná, cujas entrevistas forneceram confirmações históricas e da atualidade em relação aos etnoconhecimentos, da evolução dos conhecimentos químicos e dos remédios de origem farmacêutica e natural (GAUDÊNCIO; RODRIGUES; MARTINS; SILVEIRA, 2021).

"Os serviços ambientais são maiores do que os consumidos e atribuem a esses povos um importante papel dentro do processo de sustentabilidade em um ecossistema frágil". A partir desta afirmação, os autores, do artigo "De plantadores de farinha a colhedores de água: uma leitura epistemológica do Sistema Tradicional da Agricultura Camponesa no Maranhão", realizaram uma pesquisa de abordagem qualitativa e quantitativa, incluindo incursões etnográficas. Combase nas análises dos dados, os autores indicaram que há a importância do reconhecimento do Estado, através de políticas públicas estruturantes, como forma de validar os sistemas de produção tradicionais (DAMASCENO JUNIOR; KUBO, 2021).

\section{Em "Identidades étnicas e Etnociências nas práticas de Rezadeiras", os} autores apresentaram uma pesquisa das atividades praticadas por rezadeiras, visando identificar como as identidades étnicas são evidenciadas e como as etnociências estão associadas às atividades das rezadeiras. Através da metodologia de pesquisa bibliográfica, com cunho exploratório, descritivo e qualitativo, foram analisados 15 artigos que pautam sobre as práticas das rezadeiras, e os resultados obtidos apontaram que há semelhanças entre as práticas de rezadeiras presentes em diferentes regiões do Brasil e que essas diferenças estão relacionadas, provavelmente, às origens desses povos. Portanto, conclui-se que, em sua maioria, são de matriz africanas ou indígenas e que as semelhanças existentes ocorrem devido ao intercâmbio realizado entre algumas dessas culturas no território brasileiro (ALMEIDA; PEROVANO FILHO, 2021). 
A relação entre crianças de terreiro e os seus etnosaberes produzidos no universo do candomblé foi o foco da pesquisa realizada e apresentada no artigo "'Ewé Ó!": Crianças de terreiro e seus etnosaberes". No artigo, as autoras buscaram apresentar como as crianças de terreiro produzem seus conhecimentos através de uma afroperspectiva onde a multidimensionalidade, multirreferencialidade e a polissemia do saber se mostram, principalmente, quando essas crianças exploram o território do terreiro com a astúcia de quem conhece o que nós, adultas e adultos, não conhecemos. A partir da proodução desenhística das crianças e de suas narrativas, as autoras conseguiram indicar que se pode aprender sobre etnosaberes, cultura e ancestralidade através de itans, orikis e neolinguagens próprias dos seus universos simbólicos onde imagens e rituais didáticos unem teoria e prática, sensível e racional (SILVA; DE SANTANA, 2021).

Uma pesquisa qualitativa, após a elaboração e aplicação de uma sequência didática numa escola pública, no contexto de comunidades tradicionais, no Estado da Bahia foi realizada e apresentada no artigo "Sequência didática e comunidades tradicionais: análise do letramento científico crítico". Nele, as autoras apresentaram que os resultados obtidos na pesquisa indicaram níveis e estágios de letramento científico alcançados por cada grupo. Além disso, o presente trabalha pesquisa permitiu reflexões sobre as melhorias na sequência didática apresentada, visando ampliar os níveis e estágios de letramento alcançados pelos estudantes e abrindo margem para trabalhos futuros contendo ajustes que contribuam para o desenvolvimento da criticidade por parte dos estudantes (ARAUJO; BAPTISTA; CUNHA, 2021).

"Percursos Formativos a caminho da descolonização didática: quais enfrentamentos no Ensino das Ciências na Educação Básica?" é o título do artigo que apresenta um relato de experiência vivenciada a partir de uma formação continuada, realizada em 2019, entre docentes da Rede de Ensino do Estado da Bahia. A formação realizada teve como objetivo potencializar a descolonização de saberes científicos e do fazer didático no ensino das ciências (humanas, da natureza e exatas) da educação básica. Além do exposto, as influências de um modelo praxeológico de referência (MPR) pautado na descolonização dos saberes foi apresentado como repertório do processo formativo, integrando abordagens etnicorraciais no ensino (DA SILVA; FARIAS, 2021). 
O conceito de "História única", apresentado pela escritora Chimamanda Adichie e a canção Faraó - Divindade do Egito, do compositor Luciano Gomes, serviram de base para a pesquisa e elaboração do artigo "Indagando a "História única" no ensino de frações por meio do olho de Hórus, um Deus do Kemet". Os autores, por meio da decolonialidade e da interdisciplinaridade crítica, tiveram como objetivo subsidiar proposições de ensino em classes de Educação de Jovens e Adultos que atendam as Diretrizes Curriculares Nacionais para Ensino das Relações Étnico-Raciais. A partir da pesquisa foi verificado que os Africanos antigos foram os inventores do objeto matemático fração, bem como da sua notação atual, os quais estão registrados nos papiros keméticos, sendo o papiro de Ahmes o mais importante deles. Neste sentido, os autores recorreram ao Mito de Hórus, um deus kemético, para ressaltar que as frações estavam relacionadas ao cotidiano da civilização egípcia antiga (SILVA; FARIAS, 2021).

Ao apresentar $\bigcirc$ artigo "Circulação de saberes entre instituições: um caminho para decolonização da didática da Matemática" os autores objetivaram mostrar como a Didática da Matemática pode contribuir para o debate sobre a decolonização epistemológica de saberes no ensino da Matemática. Contribuindo com o que foi indicado, o artigo apresentado visou questionar e denunciar as práticas de ensino que tem as epistemologias do pensamento moderno colonial, eurocêntrico/ocidental como únicas formas de produção do conhecimento matemático, e que por via disso, tendem a subjugar, subalternizar, primitivizar sabedorias outras, não eurocêntricas/ocidentais. Além disso, os autores buscaram propor ações que possibilitem apresentar e discutir as sabedorias não eurocêntricas/ocidentais em espaços escolares (NHAMPINGA; FARIAS, 2021).

\section{REFERÊNCIAS}

ALMEIDA, G. S.; PEROVANO FILHO, N. Identidades étnicas e Etnociências nas práticas de Rezadeiras, ODEERE, v. 6, n. 2, 79-95, 2021. https://doi.org/10.22481/odeere.v6i2.9750

ARAUJO, G. M.; BAPTISTA, G. C. S.; CUNHA, C. Sequência didática e comunidades tradicionais: análise do letramento científico crítico, ODEERE, v. 6, n. 2, 116-133, 2021. https://doi.org/10.22481/odeere.v6i2.9790

DAMASCENO JUNIOR, J. B.; KUBO, R. R. De plantadores de farinha a colhedores de água: uma leitura epistemológica do Sistema Tradicional da Agricultura 
Camponesa no Maranhão, ODEERE, v. 6, n. 2, 54-78, 2021. https://doi.org/10.22481/odeere.v6i2.9666

DA SILVA, R. S.; FARIAS, L. M. S. Percursos Formativos a caminho da descolonização didática: quais enfrentamentos no Ensino das Ciências na Educação Básica?, ODEERE, v. 6, n. 2, 134-150, 2021. https://doi.org/10.22481/odeere.v6i2.9805

GAUDÊNCIO, J.; RODRIGUES, S. P. J.; MARTINS, D. R.; SILVEIRA, R. M. C. F. Conhecimento tradicional Kaingang: o uso de ervas medicinais, ODEERE, v. 6, n. 2, 35-53, 2021. https://doi.org/10.22481/odeere.v6i2.9793

HERRERA, M. P. M.; BARBOSA, R. H. Los conocimientos tradicionales en el ejercicio de la soberanía y seguridad alimentaria de las comunidades rurales, indígenas y campesinas, una alternativa para la sustentabilidad comunitária, ODEERE, v. 6, n. 2, 07-15, 2021. https://doi.org/10.22481/odeere.v6i2.9857

NHAMPINGA, D. A. A.; FARIAS, L. M. S. Circulação de saberes entre instituições: um caminho para decolonização da didática da Matemática, ODEERE, v. 6, n. 2, 167201, 2021. https://doi.org/10.22481/odeere.v6i2.9809

SILVA, G. R.; FARIAS, L. M. S. Indagando a "História única" no ensino de frações por meio do olho de Hórus, um Deus do Kemet, ODEERE, v. 6, n. 2, 151-166, 2021. https://doi.org/10.22481/odeere.v6i2.9877

SILVA, H. M. S.; DE SANTANA, M. "Ewé Ó!": Crianças de terreiro e seus etnosaberes, ODEERE, v. 6, n. 2, 96-115, 2021. https://doi.org/10.22481/odeere.v6i2.9875

SILVA, F.J. P.; FRAXE, T.J. Saberes de populações tradicionais: etnociência em processos de bioconservação. Contribuições a las Ciências Sociales, n.8, 2013.

VILARIM, P. R.; MARTINS, D. R.; RODRIGUES, S. P. J. Ełnoconhecimento Terena na literatura científica: um estudo bibliográfico para o Estado da Arte, ODEERE, v. 6, n. 2, 16-34, 2021. https://doi.org/10.22481/odeere.v6i2.9768 